\title{
Intergenerational Effects of Stunting on Human Capital: Where Does the Compass Point?
}

\author{
Nayan Chakravarty*, Kavita Tatwadi, Krupa Ravi
}

\begin{abstract}
Development of any nation hinges on its human capital. Human capital formation starts from early stages of childhood. Early childhood nutrition is one of the determinants of improved health and development. The purpose of this paper is to investigate the role of nutrition in impacting cognitive development, education attainment and skill development, which are the determinants of human capital. This is an attempt to analyse the intrinsic relationship between stunting and its intergenerational impact on human capital. Systemic review of literature method was put to use, to analyse the interactions between stunting and human capital. The search criteria limited the period to 30 years (1986-2017) and relevant to childhood nutrition. The search was drawn from PubMed, Web of Science and relevant independent surveys, journals and reports of repute. The study reveals that the human capital formation starts from the early stages of childhood and healthy childhood holds positive relationship to formation of human capital in the long run. Healthy childhood is largely attributed to improved nutrition which has an impact on underweight, wasting and stunting. While improvement in underweight and wasting can be achieved in short run, stunting is intergenerational and needs more long-term investments. Both nutrition specific as well as nutrition sensitive interventions play a critical role in development of robust human capital that leads to improved employability and enhanced earnings for an individual in the future. However, to have an impact on stunting, it calls for a shift in focus by augmenting investments towards nutrition sensitive domain as well, along with its present focus in nutrition specific domain. We use the evidences from South Asian and Sub Saharan countries, to make a case for India where 38 percent of children are stunted and where WASH, agriculture and women empowerment programmes do not focus on nutrition nor measure nutritional outcomes.

Key words: Human Capital, Health, Human Capital Investment, Malnutrition, Stunting, Nutrition Sensitive Intervention, Nutrition Specific Intervention.
\end{abstract}

\section{Nayan Chakravarty*, Kavita Tatwadi, Krupa Ravi Independent Policy Analysts}

Correspondence

Nayan Chakravarty,

Green Park, New Delhi, INDIA.

Mobile no: +919789982201

Email: nayan0705@gmail.com

History

- Submission Date: 17-09-2018.

- Revised Date: 15-01-2019.

- Accepted Date: 14-05-2019;

DOI : 10.5530/ijmedph.2019.4.24

Article Available online

http://www.ijmedph.org/v9/i4

\section{Copyright}

(C) 2019 Phcog.Net. This is an openaccess article distributed under the terms of the Creative Commons Attribution 4.0 International license. related to parental health history. Becker establishes links between health of an individual and education attainments and skill development of individuals, concluding that healthy individuals are more likely to possess better human capital. Since human capital formation starts from the early stage of childhood, children born to healthy parents are more likely to be healthy themselves and finally grow up to gain more years of schooling, develop better skills and become more employable.

Adequate nutrition is the key determinant of health and development of human beings. It is a crucial element for individuals, which helps them live healthy and productive lives. The World Health Organisation considers 'poor nutrition' to be the single most important threat to the world's health. About 45 percent of all child deaths are linked to malnutrition. ${ }^{2}$ In India, the nutritional status of children in 2016 was abysmal with 38.4 percent of children stunted, 21 percent wasted and 35.7 percent reported as underweight. ${ }^{2}$ Please refer Figure 1 (Annexure).

Cite this article : Chakravarty N, Tatwadi K, Ravi K. Intergenerational Effects of Stunting on Human Capital: Where does the Compass Point?. Int J Med Public Health. 2019;9(4):105-11. 
Evidence shows that malnutrition affects the economic growth of a country and transmits poverty to the next generation. Mortality and morbidity associated with malnutrition result in loss of human capital and economic productivity. Under nutrition in early childhood results in loss to the economy through education gap and consequent low-skilled workforce as undernourished children have poor cognitive functions and are more likely to dropout or have reduced school attainment. More than in underweight and wasting, the phenomenon described above is more pronounced in the case of stunting. At a microeconomic level, it is calculated that one percent loss in adult height because of childhood stunting equals to a 1.4 percent loss in productivity of the individual. ${ }^{3}$

Stunting is disturbing because the resulting loss of height and intelligence is permanent. Moreover, it is intergenerational and hence perpetuates productivity loss for individuals in the generations to follow.

Children affected by under nutrition in childhood are more likely to develop Non-Communicable Diseases (NCD) such as diabetes and heart ailments, later in life causing costly inefficiencies in the health sector. World Bank estimates the economic cost of malnutrition to be two to three percent of GDP to as much as 16 percent in highly affected developing countries. Therefore, investment in improved nutrition to arrest stunting, can result in investment of human capital intergenerational transfers.

Though the apparent reason of malnutrition is due to insufficient food intake, there is evidence that nutrition is affected by a host of other underlying factors related to poor-Water, Sanitation and Hygiene (WASH), agriculture and the status of women in the respective society. Though these factors do not directly affect the nutrition pathway, they highly influence its successful assimilation. In countries like India where the population density is 452 persons per square kilometres and access to clean water and hygiene is marred by rampant poverty, illiteracy and information asymmetry, nutrition for children is doubly compromised.

Though malnutrition has gained attention in recent years and the Indian policy makers have invested in interventions to address the problem, very little has been done to understand the genesis and contributors of its multi-dimensionality. Most of the approaches have been nutrition specific (quantity and quality of food intake) which have a short-term effect on the control of malnutrition in children. Nutrition sensitive approaches such as WASH, agriculture and women empowerment, still do not figure prominently in the nutrition improvement programmes in India, though they are known to have an indirect but a long-term effect on malnutrition.

While issues of underweight and wasting can be addressed by nutrition specific interventions, stunting which is intergenerational is hardly addressed by nutrition specific interventions. The nutritional status of the new-borns is directly affected by that of the mother before, during and after pregnancy. Stunting starts off in-utero. A malnourished mother is more likely to give birth to smaller babies continuing the cycle of stunting in future generations.

With wide gender disparity in India, the determinants of the nutritional status of the mother are embedded in the household and community context. The access to available nutrition is depended on the ability of the girl child and women to avail of it. For example, providing nutritional meals through mid-day meals in schools is a popular nutrition specific intervention of the government of India but girls from rural background usually drop out or never join schools thus depriving them access to nutrition in the first place. Similarly access to nutrition supplements during pregnancy is dependent on the societal status of the women in rural India. Women of lower castes and widows are often denied access to community health centres if they are run by higher caste staff ${ }^{4}$ thus again depriving the women and the child access to proper nutritional supplements.
Undernutrition in India is also caused due to inappropriate maternal and childcare practices, non-access to health services and unhealthy environment, including unsafe water, sanitation and hygiene (WASH). The combination of infection (especially diarrhoea and pneumonia) and under nutrition results in a vicious cycle of illness and further deterioration of nutritional status in children. UNICEF reported that India lost more than 600,000 children under five in 2010 attributed to WASH related diseases.

Improved access and availability do not automatically translate into improved dietary intake. United Nations Standing Committee on Nutrition in its review of findings of country level nutrition sensitive agriculture, suggests that it is essential to integrate nutrition education into agricultural and food system interventions for achieving social and behavioural change necessary for improved nutrition practices. Lack of knowledge about nutrition and practices can prove detrimental in usage of available nutrition.

However, the role of stunting on its intergenerational impact on human capital has not been studied thoroughly before which demands for an investigation.

\section{Purpose}

The objective of this paper is to understand how nutrition plays a role in three areas of human capital formation, namely, cognitive development, education and skill development. To this end, the paper attempts to aggregate the evidences of the influence of stunting on human capital and the influence of nutrition specific and nutrition sensitive interventions on stunting.

\section{METHODS}

A systemic review of literature was done to identify published evidence of malnutrition and its effect on human capital. A special search was made to identify the evidence of stunting and its intergenerational effects. The search covered literature from the global context to understand the genesis of human capital and its various components, the interaction between the various components and the relationship between health, nutrition and human capital. The searches were narrowed down to Africa, South-Asia and India, with a focus on low and middle-income countries, to develop a better understanding of the context, once enough evidence had been generated to establish the relationship. The inclusion criteria limited the period to 30 years (1986-2017) and only evidence that were relevant to children under five years of age were included for consideration of childhood nutritional status.

The key areas of search were health and human capital; nutrition and human capital; intergenerational effects and malnutrition; malnutrition and developing countries; and stunting. The majority of search was drawn from Web of Science, Pub Med and SAGE Publications. Further evidence was incorporated from independent reports of the World Health Organization (WHO), United Nations Children's Fund (UNICEF), Food and Agriculture Organization of the United Nations (FAO), United Nations System Standing Committee on Nutrition (UNSCN), World Bank, Global Nutrition Report $(2015,2016)$ and National Family Health Survey - 4 (NFHS 2015-16). From an initial pool of 536 full text articles (Refer Figure 2), a total of 86 published articles met the inclusion criteria. Each paper with articles relevant to the study was reviewed by three reviewers. The inclusion and exclusion criteria for the search are described in Table 1. Inclusion Criteria (Annexure).

To avoid publication bias we have reached out to some of the authors to access research that may have shown negative results, or research that is yet to be published but is probing the non-relationship of nutrition and WASH and agriculture. Given the time constraints we have not been 
able include any such studies in this review as we are yet to receive any response from them.

\section{RESULTS}

\section{Health as Human Capital}

Theories on human capital have traditionally explored the dimensions of education and training and skills that make individuals-assets in the labour markets. The theory of human capital investment attributes the differences in earnings of individuals to the differences in talents, family background and bequests and other assets. ${ }^{5}$ Economists have attributed higher returns to the more educated and better trained. However, a relatively new field of health as human capital emerged as economists saw the returns of health in building human capital and the costs of diseases and illness to the labour market. The inclusion of health as a form of human capital rests on three interrelated developments-(i) An analysis of optimal investments in health by individuals, pharmaceuticals and governments, (ii) The willingness of people to pay to survive longer, (iii) The importance of 'complementarities in linking health to education and other forms of human capital investments', such as learning skills. ${ }^{6}$

Since human capital formation starts from the early stages of childhood, importance of a healthy childhood is necessary for a robust human capital formation. To understand the impact of health shocks during early stages of human development, Nilsson (2009) states that through direct (via neurological insults) and indirect channels (subsequent investments and skill formation), formation of human capital is limited in the long run.

Even in the long run, health is an integral form of human capital. Neidell and Zivin (2013) provide strong evidence on how exposure to pollution, an environmental threat, leads to poor observable and unobservable health outcomes. This, in turn, has an adverse impact on human capital, including years of schooling, cognitive ability and productivity. They further indicate that poor health can 'contemporaneously' impact earnings by increasing worker absenteeism and diminishing worker productivity for adults and absenteeism from school for children.

\section{Effects of Malnutrition on Human Capital}

Studies have revealed that malnutrition and undernutrition have negative effects on human capital. Poorly nourished children are more likely to complete fewer years of school and have lower productivity as adults, including 10 percent lower earnings over their lifetime (Horton, 1999). Poor nutritional status in children leads to issues of underweight, wasting and stunting. Out of these, stunting is long term and cannot be cured through nutritional intakes alone. The prevalence of stunting is also a good indicator of inequalities of human development. ${ }^{7}$

In 2008, in a study on maternal and child undernutrition and its effects on human capital, the authors noted that under nutrition was strongly associated with less schooling, reduced economic productivity and for women-lower offspring birth weight. The authors emphasised that stunting (height for age at 2 years) is the best predictor of human capital and under nutrition is associated with lower human capital. The group concluded that childhood stunting is linked to short adult stature, less schooling, impaired intellectual functioning and less income as adult. Hence damage suffered during early childhood (under the age of two years) leads to permanent impairments and is most likely to be transferred to the next generation. Prevention of this damage can lead to health, education and economic benefits. ${ }^{8}$

According Adair, et al. (2008) too, stunting in the first two years of life leads to irreversible damage. In the short run, the child is susceptible to a weaker immune system, pneumonia and diarrhoea. But as stunted children become adults, their likelihood of suffering from chronic diseases increases and it leads to shorter adult height, lower attained schooling, reduced adult income and decreased off spring birth-weight. It has been estimated that poor nutrition can decrease a nation's economic growth by at least 8 percent, owing to direct losses in productivity, poorer cognition and reduced schooling. ${ }^{9}$

Stunting is a cyclical process that has devastating inter-generational consequences for socio-economic and health outcomes at the individual, community and national levels. Women who were themselves stunted in childhood tend to have stunted offspring, creating an intergenerational cycle of poverty and reduced human capital that is difficult to break. ${ }^{10}$ This indicates that by arresting inter-generational stunting, the devastating socio-economic and health consequences would diminish, which would lead to an improvement in human capital.

\section{Malnutrition and Nutrition Specific Interventions}

Since the late nineties researchers have professed the nutrition specific investment (micro-nutrients interventions and breast feeding promotion) as cost effective as basic child survival initiatives for low-income countries in Asia. The recommendations included strengthening monitoring of salt iodization, extension of Vitamin A mass dose coverage, establishing Vitamin A fortification programs, establishing iron fortification and intensifying coverage of iron supplementation to pregnant women, promotion of breast feeding and building on successful community-based nutrition programs. ${ }^{11}$ The problem of malnutrition was seen as 'syndrome of development impairment' as it affected cognitive and behavioural development, poor immunity and increased morbidity and mortality. Since these cluster of nutritional problems start in utero to first three years of the child's life, prevention of low birth weight and promotion of adequate growth through nutrition specific interventions was considered beneficial for long term economic strategies. ${ }^{12}$

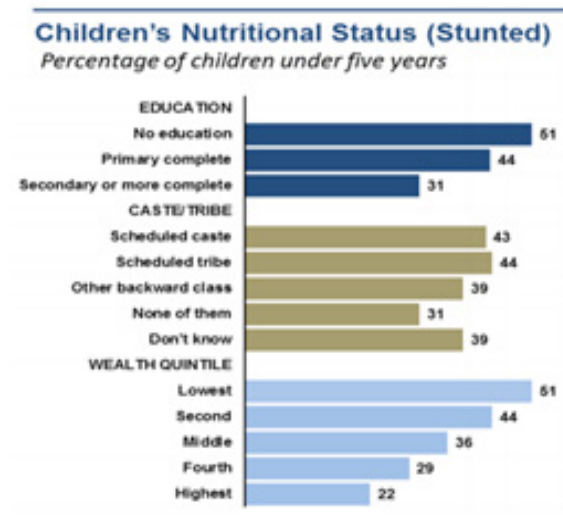

Figure 1: Children's Nutritional status. National Family Health Survey - 4 (NFHS, 2015-16)

\begin{tabular}{|c|c|c|}
\hline s.no & Criteria & Inclusion \\
\hline 1 & Time Period & Within the time-period 1986-2017 \\
\hline 2 & Language & English \\
\hline 3 & Place of Study & Low and Middle-income countries \\
\hline 4 & $\begin{array}{l}\text { Geographical } \\
\text { Dimensions }\end{array}$ & No limitations \\
\hline 5 & Study Population & $\begin{array}{l}\text { Children under } 5 \text { years, for child nutritional } \\
\text { status and mothers. }\end{array}$ \\
\hline 6 & $\begin{array}{l}\text { Aspects to be } \\
\text { covered in the study }\end{array}$ & $\begin{array}{c}\text { Stunting, Human Capital, Nutrition sensitive } \\
\text { interventions }\end{array}$ \\
\hline
\end{tabular}




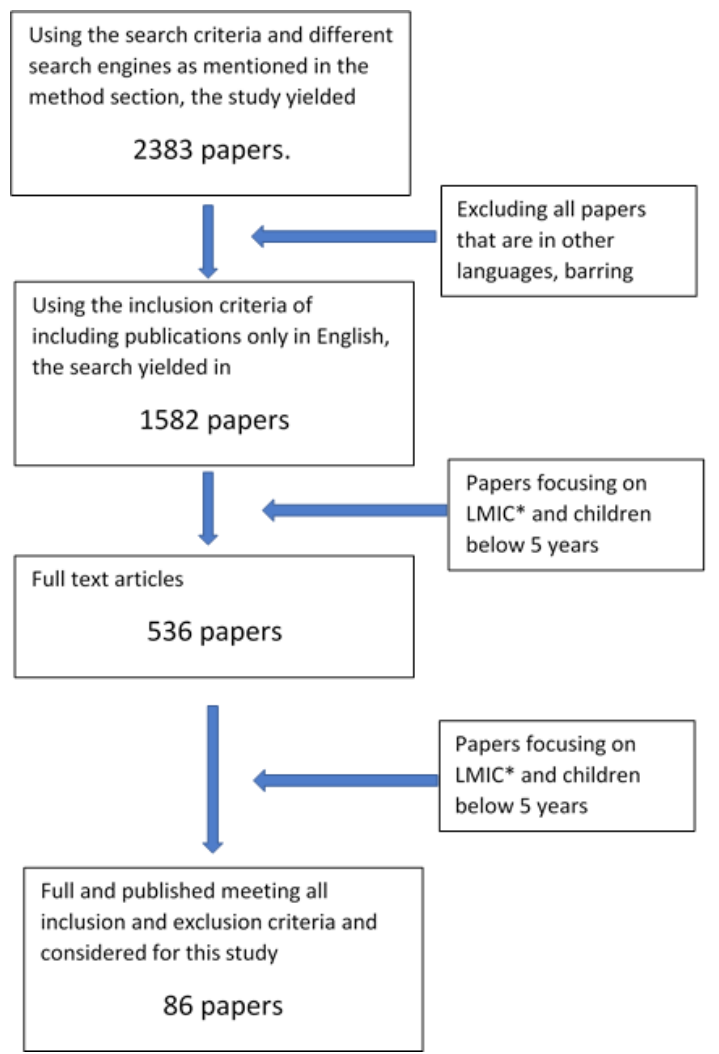

Figure 2: Diagram highlighting the different stages of using the identified inclusion and exclusion criteria.

* Low and Middle-Income Countries (LMIC)

The South African Child Support Grant that targeted child support payments to children's caregivers (exclusively to women) was found to bolster childhood nutrition as signalled by child height-for-age as these were unconditional transfers for children below seven years of age. ${ }^{13} \mathrm{~A}$ study that covered the national Vitamin A program of India for preschool children found that prevalence of stunting, severe stunting, underweight and severe underweight was higher among children who did not receive Vitamin A compared to those who received it and concluded that expanded coverage of the vitamin A supplementation program in India will protect children from morbidity, mortality and blindness. ${ }^{14}$

Mid-day meal program or school-lunch program started in the sixties in India. In 1994 it was improved to compulsorily include micronutrient supplements of iron and Vitamin A and iodine fortified salt. An evaluation of the mid-day meal programme from 1993-96 showed a positive impact of the program on the nutrition status of the students. The students who received the supplements were $1.1 \mathrm{~kg}$ heavier and 1.1 $\mathrm{cm}$ taller than those who did not. Their haemoglobin levels were $>12 \mathrm{~g} /$ $\mathrm{dL}$ and their intestinal parasite prevalence rates dropped from 71 to 39 percent. The prevalence of night blindness and Vitamin A deficiency reduced from 67 to 34 percent. ${ }^{15}$ However, some authors argue that many of the nutrition studies of school lunch programme are controlled trials in which many components of the interventions are closely managed and hence the external validity of these studies for programme implemented in the field is often difficult to ascertain. ${ }^{16}$

While the delivery of mid-day meal in schools was initially shrouded in operational difficulties, it was debated that the programme is difficult to scale by government staff and should be handed over to NGOs for better implementation. However, a study found that mid-day meal provided by NGOs had no better impact on growth of the primary school children though it reduced prevalence of vitamin deficiency significantly, compared to the programme run by local government bodies in India. ${ }^{17}$

Many interventions implemented at scale, show evidence of effectiveness of 'nutrition specific' interventions, in reducing malnutrition in children. The Lancet Series on Maternal and Child Undernutrition in 2008 did a comprehensive update on such interventions. The data from 34 countries (that has 90 percent of world's stunted children) was examined. The study concluded that deaths of children under five years can be reduced by 15 percent if the population can access ten evidence-based nutrition interventions and one fifth of the stunting can be averted if accesses to these interventions are improved. ${ }^{18}$

The analyses were conducted in four sub-saharan countries and authors drew from it to show that the investment in these ten interventions can prove very cost-effective in South Asian countries also if considered as a package as it will enhance allocative efficiency of nutrition resources. ${ }^{19}$ Another nutrition specific programme in India is the Integrated Child Development Services (ICDS), a huge part of which is supplementary feeding for malnourished children. After eight years of its launch in 1975 a study measured the impact of the programme and found that the programme achieved a significant decline in malnutrition among preschool children compared to children who received nutrition and health care through separate programmes. ${ }^{20}$

Despite a significant economic growth in India and a significant spending on ICDS, the levels of child malnutrition fell very slowly during the 1990s. Researchers found that the programme placement was regressive across states. The states with the greatest need for the programme had the least coverage and the lowest budgetary allocation from the central government. Little impact of the programme was found in the villages having ICDS centres. ${ }^{21}$

ICDS has several mismatches between the programme's design and actual implementation that prevent it from reaching its potential. There is an increasing emphasis on the provision of supplementary feeding children aged four to six years at the expense of other crucial components. Moreover, it failed to effectively reach children under three. ${ }^{22} \mathrm{~A}$ study did find significant effects for the most malnourished children but the results also suggested that though ICDS effectively targets poor areas, it fails to target areas with low levels of average education and with unbalanced sex ratios. ${ }^{23}$ While another study found that girls aged zero to two years receiving supplementary feeding were at least one $\mathrm{cm}$ taller than those not receiving it in rural India. The estimates were similar for boys aged zero to two years but were less robust. ${ }^{24}$

The other problem with ICDS is the lack of knowledge and awareness about ICDS among the anganwadi workers (who are the implementers of the programme in the rural health centres) in despite the training they received. A study in the Purmandal block of Jammu, India showed that only 55 percent of Anganwadi workers were aware of nutritional services provided at their centres and were able to explain it. While 30 percent of them were unaware of the method of assessment of nutritional status of children while they were responsible for assessing it and none of them were aware of energy and protein requirement of the targeted age group of children. Though they maintained growth charts records for children 65 percent of them were unaware of the significance of a growth chart. ${ }^{25}$ Accelerated gains are possible in achieving the nutrition goals through continued 'nutrition specific' interventions for better maternal health and better delivery of micronutrients to the zero to three-year-old children. While this can be achieved through robust delivery strategies and community engagement to reach the 'at-risk' population, the strategy will gain immensely if linked to nutrition-sensitive approaches like women empowerment, agriculture, food systems, social protection and safety nets. 


\section{Malnutrition and Nutrition Sensitive Interventions}

Though food is the basic source of nutrition and agriculture the mode for producing food, most of the agriculture interventions for reducing poverty have focussed on increased food production but not necessarily on increasing the nutritional outcomes of the food produced and consumed. Study that investigated the impact of agriculture intervention on nutritional status of participating households concluded that the programmes that invested in at least four out of five capitals (physical, natural, financial, human and social), had a positive effect on nutrition outcomes. ${ }^{26}$ Since most of the rural population in developing countries depends on staple crops for sustenance, these crops can be enriched (biofortified) with micronutrients using plant breeding or transgenic strategies. In addition, micronutrient enrichment of seeds can increase crop yields ensuring adaptation by farmers. ${ }^{27}$

Though agriculture is the primary source of livelihood for the majority of nutritionally vulnerable households in India, there are gaps in evidence and data currently available that establish the pathways between agriculture and nutrition. To effectively establish the linkages and enhance the nutrition sensitivity of agriculture in India, the data and policy disconnects need to be bridged. ${ }^{28}$ Researchers have assessed two channels of pathways in agriculture and nutrition linkage. A food consumption pathway where consumption practice of specific foods affect the nutrition outcome of consumers and a maternal employment-time use pathway, where the time of mother away on agriculture farms affects the new born's nutritional intake and hence affects the growth and have argued for pro-nutrition agricultural policies. ${ }^{29}$

In India, agriculture has a range of important influence on nutrition. It influences diets and food practices. There is low evidence of genderagriculture link to nutrition outcome but this is because of inadequate research in this field. Closing this gap is essential to strengthen the agriculture sector's contribution to reduction of under-nutrition in India. ${ }^{30}$

A study that links various pathways of maternal education and child nutritional status in Bolivia suggests that socio-economic factors are the most important pathways linking maternal education and child nutritional status and the modern attitudes about health care also explain impact of education. Reproductive behaviour also appeared to influence nutritional status independent of maternal education. ${ }^{31}$

Though the effect of nutrition specific interventions on women's nutrition status, birth outcome and stunting rates in South Asia are well documented, growing evidence directs to the role of non-nutritional factors impacting women's nutritional status and birth outcomes, caring practices and nutritional status of children. Evidence unravels the important role of early age marriage and conception, poor secondary education, domestic violence, inadequate decision making power, poor control over resources, strenuous agriculture activities, increasing employment of women and interventions such as cash transfer scheme and microfinance on undernutrition in children. Evidence suggests that it is important to reach women during adolescence, prevention of early marriage and conception, ensuring women enter pregnancy with adequate health, completion of secondary education, enhancement in purchasing power of women, reduction of work drudgery and elimination of domestic violence. These are gender specific nutrition sensitive interventions in South Asia that have a positive effect on the nutrition outcome of the mother and the new born baby. ${ }^{32}$

In South Asia women face a double burden of diminished social status and in-access to resources. Options for enhancing diets during pre-natal and post-natal periods are restricted to dietary practices of the community and availability of nutrition rich diet for the women. Dietary diversification and increased intake of nutrient-rich foods improved complementary feeding practices, micronutrient supplements and forti- fied foods specifically designed for these targets, prevention of post-natal infections and care for women and children, can result in reduction of malnutrition (especially stunting) and can enhance human capital. ${ }^{33}$

While women empowerment plays an important role in reducing malnutrition in new-borns, the environment that surrounds the new born too plays a crucial role in ensuring that the mother and new born remain disease free. Remaining infection free in the first 1000 days of life is very crucial for a new born as it affects the nutritional status of the baby in the long run. Earlier there were inconclusive evidences that suggested that WASH interventions confer small benefit on growth in children under five, but this was mainly due to relatively short-term studies, with nonrobust methodologies. ${ }^{34}$

There is an increasing interest in understanding how WASH affects malnutrition (especially stunting) and how it can be effectively delivered to reduce the intergenerational effects of stunting. Growing evidence suggests that WASH conditions have significant detrimental effect on child growth and development resulting from sustained exposure to enteric pathogens and due to wider socio-economic mechanisms. Therefore, universal access to WASH services and modified WASH strategies that address exposure pathways in the first two years of life is needed to arrest stunting. ${ }^{35}$

The evidence of pathways of WASH interventions and stunting are still under construction as large-scale studies are underway in South Asia and Sub Saharan Africa. However, a recent Cochrane review reports that the effect of WASH interventions on child stunting was highest in children in the age of zero to 23 months. ${ }^{34}$

A study that evaluated the impact of Helen Keller International's (HKI) programme of Enhanced Homestead Food Production (EHFP) programme, that increases availability and intake of diverse micronutrientrich foods and promotes optimal nutrition and hygiene practice among poor households, throughout the year, concluded that nutrition sensitive interventions show positive result when used as a package. The sale of surplus produce had increased, the use of transformative gender approach had empowered women, improved range of practices that impact child growth (in and RCT in Nepal), while a non-RCT study showed 10.5 percent reduction in stunting in Nepal and 18 percent reduction of stunting in Bangladesh. Based on these results EHFP has evolved into an integrated package of agriculture, nutrition, WASH, linkage to health care, women's empowerment, income generation and advocacy. ${ }^{36}$

\section{DISCUSSION}

\section{Nutrition Status of Children in India}

Ever since the Millennium Development Goals 4 (MDG) called for reduction of child mortality (under five age) by two third by 2015, developing countries have made impressive achievements in reducing child mortality. Still majority of deaths occur in Sub-Saharan Africa and South Asia. India is one of the five countries in South Asia that has high child mortality. The major causes of child mortality are attributed to diarrhoea, respiratory tract infections, sepsis and in variably in most of these cases, malnutrition is an underlying cause. Despite the global efforts, malnutrition is a significant problem in India. In 2016, the National Health and Family Survey reported that 38.4 percent children were stunted, 21 percent were wasted and 35.7 percent were underweight.

There are many causes of under nutrition from lack of adequate food intake by the expectant mother, to up to two years after birth when rapid growth occurs, poor quality of neo-natal and child care and high prevalence of infections that deplete the nutrition in a child or inhibit assimilation of nutrition. Though the national programme of Integrated Child Development Services (ICDS) has been providing nutrition and health- 
care to mothers and new born for long, the nutritional status of children has remained low.

India has the largest number of children (under-five years) who are stunted-that is, 48 million (Water Aid, 2016). This is more than four times the number in countries such as Pakistan and Nigeria. ${ }^{37}$ According to the Lancet series on maternal and child under nutrition, the prevalence of stunting is slowly decreasing globally, but has affected at least 165 million children younger than five, in $2011 .{ }^{38}$ Defined as "the percentage of children, aged 0 to 59 months, whose height for age is below minus two standard deviations (moderate and severe stunting) and minus three standard deviations (severe stunting) from the median of the WHO Child Growth Standards" (UNICEF, 2013), stunting reflects chronic under nutrition during the most critical periods of growth and development in early life.

\section{Stunting and its Effect on Human Capital in India}

The National Family Health Survey (NFHS) 2015-16, reveals that among the total number of stunted children under five, 51 percent has no education. Also, more than half of the stunted children under five belong to the lowest wealth quintile. This gives rise to two major implications. First, stunting negatively affects the level of education, thus reducing human capital. Second, since more than a half of stunted children under five belong to the lowest wealth quintile, it implies that one of the factors affecting stunting is the socio-economic status of the household.

UNICEF (2013), in its report "Improving Child Nutrition: The achievable imperative for global progress", has provided a conceptual framework of malnutrition, which captures the intergenerational consequences and the immediate, underlying and basic causes of malnutrition. It can be demonstrated that over and above the immediate and underlying causes of malnutrition, there exist three basic causes including household access to adequate quantity and quality of resources, inadequate financial, human, physical and social capital and the socio-cultural, economic and political context that heavily influence maternal and child undernutrition.

Malnutrition is multidimensional in India. Any single intervention alone is not poised to help achieve long term success. Sustainable nutrition outcomes require collaborative multi-sectoral approach. Hence nutrition specific (quality and quantity) and nutrition sensitive (WASH and agriculture) interventions are equally important to effect the change. While wasting and underweight can be taken care of by nutrition specific interventions, stunting can be addressed by long term investments in nutrition sensitive interventions thus arresting its intergenerational effect on the Indian economy. If not arrested, stunting shall continue having an adverse impact on cognitive development, education and skill development, thereby hindering human capital formation.

There is a lack of political will towards long term investments, to arrest stunting. Often the focus of political power is on low hanging fruits, through which short term results may be achievable and shown. However, to deal with an intergenerational phenomenon like stunting, there is a need for strong political commitment towards long term, nutrition sensitive investments.

\section{CONCLUSION}

It is known that stunting is intergenerational and cannot be addressed through nutrition specific intervention alone. This paper has aggregated strong evidence from South Asia and India, on how stunting adversely impacts the formation of human capital. Further, the paper has revealed that stunting negatively affects cognitive ability, education and skill development and thus jeopardises labour productivity and human capital for an economy. A way out of this intergenerational trap of stunting is by focusing policies and investments on long term investments in nutrition sensitive interventions. This is also getting evident that, most of the nutrition sensitive intervention such as WASH, agriculture and women empowerment, do not measure its effect on nutritional status of children as this is not the primary objective of the interventions. It is therefore necessary that the objectives of all these interventions be enhanced to measure their respective impacts on maternal and child nutritional status, so that nutrition-sensitive interventions can be clubbed along with nutrition specific interventions to arrest stunting and its intergenerational and its impact on human capital. The study highlights the limitations of the present nutritional interventions and calls for an alternative action. This study calls for an action of understanding the problem of childhood stunting well, through Trans-Disciplinary-Research approaches and finding ways to address the complex societal challenges and limiting many of the Indian children, reaching their full potential.

\section{Limitation of the Study}

The study draws its relevance from published secondary literature, which may be skewed towards western perspective, as most of the publication and the researchers were from the west. As indicated, most of the papers were written by researchers from the west and hence there could be researcher biases in their perspective to understand the research question, focusing at Low and Middle-income countries (LMIC).

The study calls for understanding the complex societal challenge by using Trans-Disciplinary-Research (TDR) approaches on the complex problem of stunting by understanding the problem from different perspective and hopefully shaping the future interventions and programs.

\section{ACKNOWLEDGEMENT}

Nothing to declare.

\section{CONFLICT OF INTEREST}

The authors declare no conflict of interest.

\section{ABBREVIATIONS}

WASH: Water and Sanitation; NCD: Non-Communicable Disease; NGO: Non-Government Organization; TDR: Trans Disciplinary Research.

\section{REFERENCES}

1. Becker GS. Human capital revisited. In Human capital: A theoretical and empirical analysis with special reference to education. University of Chicago Press. $1994 ; 15-28$

2. WHO. Stunted growth and development: Context, causes and consequences. 2017 Available from: http://www.who.int/nutrition/childhood_stunting_framework_leaflet_en.pdf?ua=1 (Last received on ...)

3. Visser J. The Effect of Childhood Stunting on Adult Life; Radboud Universiteit Nijmegen. 2016;7-14.

4. Meyerhoff S. The Intergenerational Cycle of Malnutrition: How Gender and Social Status Doom Many Mothers and New-borns. New Security Beat. 2014. Available from: https://www.newsecuritybeat.org

5. Becker GS, Tomes N. Human Capital and the Rise and Fall of Families. J of Labor Economics. 1986;4(3):1-39.

6. Becker GS. Health as human capital: Synthesis and extensions. Oxford Economic Papers. 200759(3):379-410

7. Onis MD, Frongillo EA, Blossner M. Is malnutrition declining? An analysis of changes in levels of child malnutrition since 1980. Bulletin of the World health Organization. 2000;78(10):1222-33.

8. Hoddinott J, Ruel M. Investing in early childhood nutrition. IFPRI Policy Brief. 2008;8:1-3.

9. Horton S. Opportunities for Investments in Nutrition in Low-income Asia. Asian Development Review. 1999;17(1-2):246-73.

10. Humphrey JH, Prendergast AJ. The stunting syndrome in developing countries. Paediatrics and International Child Health. 2014;34(4):250-65.

11. Horton S, Levin C. Iron deficiency anemia: Re-examining the nature and magnitude of the public health problem. The Journal of Nutrition. 2001:131(2-S2):691-6. 
12. Martorell R. The nature of child malnutrition and its long-term implications. Food and Nutrition Bulletin. 1999;20:288-92.

13. Aguero J, Carter M, Woolard I. The impact of unconditional cash transfers on nutrition. United Nation Development Programme. 2007;39.

14. Semba RD, De PS, Sun KB, Raju VK. The role of expanded coverage of the national vitamin a program in preventing morbidity and mortality among preschool children in India. J of Nutrition. 2010;140(1):208-12.

15. Gopaldas T. Improved effect of school meals with micronutrient supplementation and deworming. Food and Nutrition Bulletin. 2005;26(2 Suppl 2):220-9.

16. Adelmen S, Gilligan D, Lehrer K. How effective are food for education programs?: A critical assessment of the evidence from developing countries. Intl Food Policy Res Institute. 2008;9.

17. Sharma AK, Singh S, Meena S, Kannan AT. Impact of NGO run mid-day meal program on nutrition status and growth of primary school children. Indian Journal of Paediatrics. 2010;77(7):763-9.

18. Bhutta ZA, Das JK, Rizvi A, Gaffey MF, Walker N, Horton S, et al. Evidencebased interventions for improvement of maternal and child nutrition: What can be done and at what cost?. The Lancet. 2013;382(9890):452-77.

19. Shekar M, Dayton EJ, Kakietek J. The costs of stunting in South Asia and the benefits of public investments in nutrition. $J$ of Maternal and Child Nutrition. 2016;12(Suppl 1):186-95.

20. Tandon BN. Nutritional interventions through primary health care: Impact of the ICDS projects in India. Bulletin of the World Health Organization. 1989;67(1):7780.

21. Das GM, Lokshin M, Grangolati M, Ivaschenko O. Improving Child Nutrition Outcomes in India: Can the Integrated Child Development Services Program Be More Effective?. Policy Research Group: The World Bank. 2005;3647.

22. Gragnolati M, Bredenkamp C, Gupta MD, Lee YK, Shekar M. ICDS and persistent undernutrition: Strategies to enhance the impact. Economic and Political Weekly. 2006;1193-201.

23. Kandpal E. Beyond average treatment effects: Distribution of child nutrition outcomes and program placement in India's ICDS. World Development 2011;39(8):1410-21.

24. Jain M. India's Struggle against Malnutrition- Is the ICDS Program the Answer?. World Development. 2015;67:72-89.

25. Manhas S, Dogra A. Awareness among Anganwadi workers and the prospect of child health and nutrition: A study in Integrated Child Development Services (ICDS) Jammu, Jammu and Kashmir, India. The Anthropologist. 2012;14(2);171-
26. Berti PR, Krasevec J, Fitz GS. A review of the effectiveness of agriculture interventions in improving nutrition outcomes. J of Public Health Nutrition. 2004;7(5):599-609.

27. Welch RM, Graham RD. Breeding for micronutrients in staple food crops from a human nutrition perspective. Journal of Experimental Botany. 2004;55(396):35364.

28. Gillespie S, Harris J, Kadiyala S. Agriculture-Nutrition Disconnect in India: What Do We Know?. IFPRI Discussion Paper. 2012;01187.

29. Headey D, Chiu A, Kadiyala S. Agriculture's role in the Indian enigma: Help or hindrance to the crisis of undernutrition?. J of Food Security. 2012;4(1):87-102.

30. Kadiyala S, Harris J, Headey D, Yosef S, Gillespie S. Agriculture and nutrition in India: Mapping evidence to pathways. Annals of the New York Academy of Sciences. 2014;1331:43-56.

31. Frost MB, Forste R, Hass DW. Maternal education and child nutritional status in Bolivia: finding the links. J of Social Science and Medicine. 2005;60(2):395-407.

32. Vir SC. Improving women's nutrition imperative for rapid reduction of childhood stunting in South Asia: coupling of nutrition specific interventions with nutrition sensitive measures essential. J of Maternal and Child Nutrition. 2016;12(Suppl 1):72-90.

33. Dewey KG. Reducing stunting by improving maternal, infant and young child nutrition in regions such as South Asia: evidence, challenges and opportunities. $\mathrm{J}$ of Maternal and Child Nutrition. 2016;12(Suppl 1):27-38.

34. Dangour AD, Watson L, Cumming O, Boission S, Velleman Y, Cavill S, et al. Interventions to improve water quality and supply, sanitation and hygiene practices and their effects on the nutritional status of children. Cochrane Database Syst Rev. 2013;8:CD009382.

35. Cumming O, Cairncross S. Can water, sanitation and hygiene help eliminate stunting? Current evidence and policy implications. J of Maternal and Child Nutrition. 2016;12(Suppl 1):91-105.

36. Haselow NJ, Stormer A, Pries A. Evidence-based evolution of an integrated nutrition-focused agriculture approach to address the underlying determinants of stunting. J of Maternal and Child Nutrition. 2016;12(Suppl 1):155-68

37. Ravi S, Singh R. Nutrition in India: Targeting the first 1000 days in a child's life. Brookings India. 2016;1-10.

38. Black RE, Victora CG, Walker SP, Bhutta ZA, Christian P, Onis M, et al. Mater nal and child undernutrition and overweight in low-income and middle-income countries. The Lancet. 2013;382(9890):427-51.

Cite this article : Chakravarty N, Tatwadi K, Ravi K. Intergenerational Effects of Stunting on Human Capital: Where does the Compass Point?. Int J Med Public Health. 2019;9(4):105-11. 